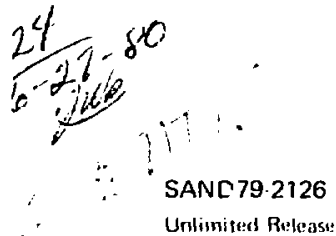

$$
\text { Mirisier }
$$

\title{
A Consistent Stress-Strain Ductile Fracture Model as Applied to Two Grades of Beryllium
}

Tom G. Priddy, Steve E. Benzley, L, Mike Ford

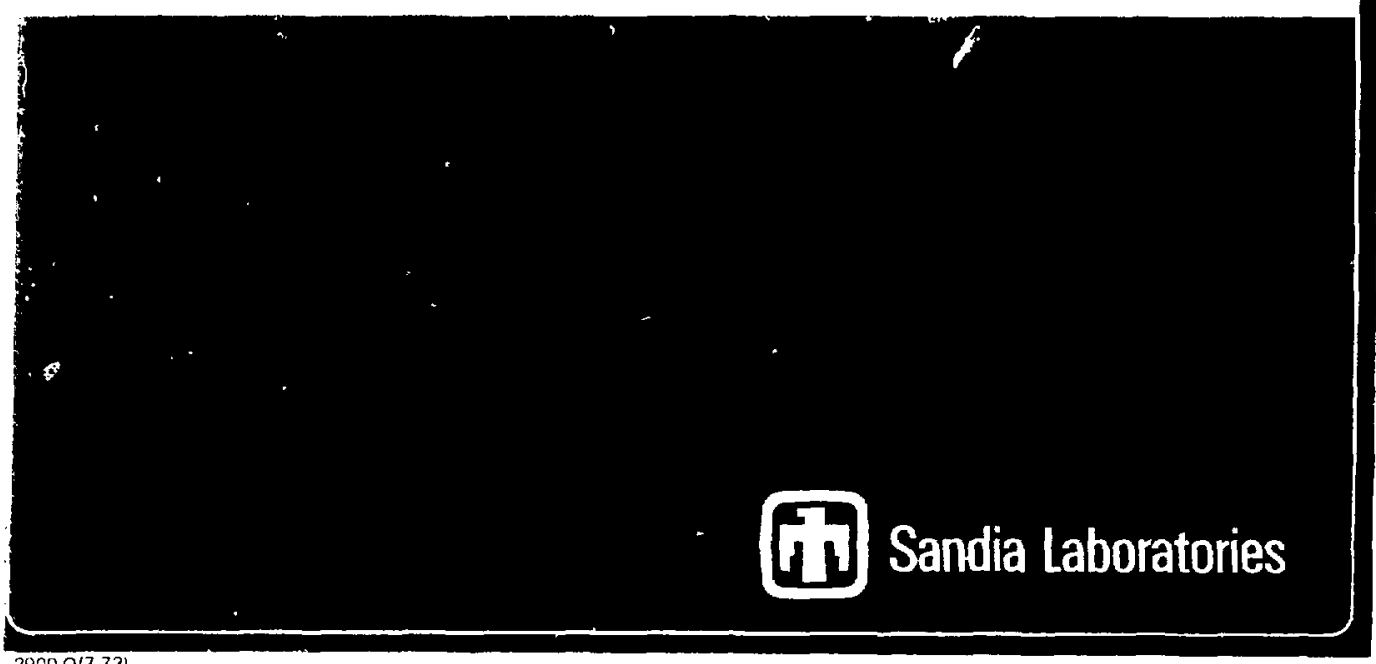


SAND79-2126

Unlimited Release

A CONBISTEHT STRESS-STRAIN DUCTILE

FRACTURE MODEL AS APPLIED TO TWO GRADES OF BERYLLIUH*

T. G. Priddy, S. E. Benzley, and L. M. Ford Applied Mechanics Division 5522

Bandia Laborator les ${ }^{\dagger}$

Albuquerque, New Mexico 87185

\section{ABSTRACT}

Published yield and ultimate biaxial stress and strain data For two grades of beryllium are correlated with a more complete method of characterizing macroscopic strain at fracture initiation in ductile materials. Results are compared with those obtained $\mathrm{from}$ an exponential, mean stress dependent, model. Simple statistical methods are employed to illustrate the degrae of correlation for each method with the experimental data.

* This work was supported by the U. S. Department of Energy under Contract AT (29-1)-789.

t A. S. Department of Energy Facility.

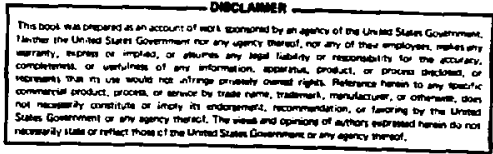

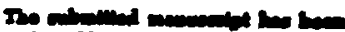

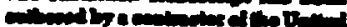

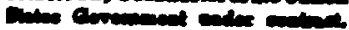

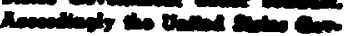

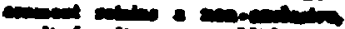

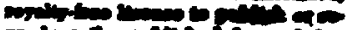

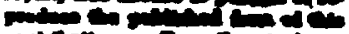

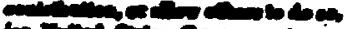

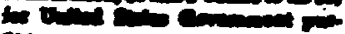
rime 
A Consistent Stress-strain Ductile Fracture

Model as Applied to Two Grades of Beryllium

\section{IATRODUCTION}

Two methods of correlating effective plastic strein at fracture of ductile solids are discussed in this report. One of these 1s a mathematical model based upon void growth kinematics noted by Mccilintock ${ }^{1}$ and by Rice and Tracey ${ }^{2}$. These resuits provide evidence of rapidly decreasing ductility with the tensile mean atress. Hancock and Mackerzie ${ }^{3}$ used Rice and Tracey's results to represent the effective plastic strain at fracture as

$$
\bar{\varepsilon}_{p}=n \exp ^{-\frac{3}{2}\left(\sigma_{m} / \bar{\sigma}\right)}
$$

where the auctility as measured in terms of the effective plastic strain (i.e., equare root of the second invariant of the deviator strain tensor) at fracture is a Eunction of the average stress $\sigma_{m}$, and $\bar{\sigma}$ which is the root mean square of the "princlpal shear stresses". Th1s equation was used to good advantage by Hancock and Mackenzle in the correlation of experimental data taken from tests of varlous high strength steels.

${ }^{1}$ Superscript numbers refer to simllarly numbered references at end of report. 
The second method of analysis is an extension of the dual strength characterization model reported in Reference (1). In this previous etudy a mathematical nodel of fracture in multi-axial strese space was proposed. Yleld and ultimate atrength surtaces for two grades of beryllium were jointly displayed. These aufaces wore quantified and compared with experimental data reported by Lindholm, et al. 5 Ductility (the stress-space region which corresponds to plastic flow) was shown to decrease under triaxial stress and vanish at the intersection of the yield and ultimate surfaces. While this stress space model is theoretically complete for work hardening materials, plastlc strain at fracture is a more convenient, senditive, and practical measure of ductllity. Also, because the strain data scatter may be wider than the associated scattar in the strength data, statistical bounds based on strain measuremente are deaired.

The data for the two grades of beryllium measured by Lindholm et $a^{5}$ have therefore been re-studied to:

1. correlate the beryllium failure strain data with a mathematical model,

2. introduce a failure stress to failure strain transformation model to be usea in conjunction with the stress space model of Reference 4 , and 
3. show that the three elements: stress at fracture, strain at fracture, and fallure stress to failure strain model can be jointly used to consistently characterize macroscopic fracture of ductile solids.

Data reduction and correlation using Equation (1), were also attempted and these results are illustrated for comparison with those from the current model. Elementary statistical methods were used to predict data scatter bounds and to Indicate the precision of the separate methods.

\section{DISCUSBION OF MATHENTICAL NODELS}

Two methods are used in this study to correlate the strain data measured by tindholm, et al. For two grades of beryl11um. The exponential model, Iquation (1) was generalized by cubetituting an unknown but to be deterained constant (k) for the factor $3 / 2$, 1.e..

$$
\bar{\varepsilon}_{\mathrm{p}}=\lambda \exp -k\left(\sigma_{m} / \bar{\sigma}\right)
$$

The paraneters in Equation (2) are defined for use in this study by Equatione (3): 


$$
\begin{aligned}
& \varepsilon_{p}=\frac{\sqrt{2}}{3}\left[\left(\varepsilon_{1}-\varepsilon_{2}\right)^{2}+\left(\varepsilon_{2}-\sigma_{3}\right)^{2}+\left(\varepsilon_{3}-\varepsilon_{1}\right)^{2}\right. \\
& \left.+6\left(\varepsilon_{12}^{2}+\varepsilon_{23}^{2}+\varepsilon_{31}^{2}\right)\right]^{1 / 2} \\
& \sigma_{m}=\frac{1}{3}\left(\sigma_{1}+\sigma_{2}+\sigma_{3}\right) \\
& \sigma=\frac{1}{\sqrt{2}}\left[\left(\sigma_{1}-\sigma_{2}\right)^{2}+\left(\sigma_{2}-\sigma_{3}\right)^{2}+\left(\sigma_{3}-\sigma_{1}\right)^{2}\right. \\
& \left.+6\left(\tau_{12}^{2}+\tau_{23}^{2}+\tau_{31}^{2}\right)\right]^{1 / 2}
\end{aligned}
$$

where,

A = constant to be determined from test data and

$k$ = constant, deternined simultaneously with the parameter A from two independent states of stress-strain data at fracture.

This exponential model is described well in the referenced Iiterature and it is founded on experimental observation and calculations of the kinematics of void growth. The nodel is expected to be linited to a partcular range of tensile mean stress, however, since pure dilatation should lead to fracture without plastic strain and the model predicts a rapid increase in ultimate plastic atrain (and strength) with compressive mean stress. 
The second nethod of analysis is an extension of the dual strength characterization model reported in Reference (4). In that report, a wide range of blexial strength data were accurately correlated with the cublc stress space model given in Reference (6). Figure (1) is an lilustration of this dual yield and ultimate strength model. Note that in the deviatoric plane the ultimate surface is not circular. A scalar function of stress such as $\sigma$ is not constant on this surface at a fixed value of $\sigma_{m}$ but has rotational dependence. The parameter $T$ is used to make this distinction. $T$ is defined as the amplitude of the deviatoric stress vector and it is calculated from a principal stress state with Equation (4).

$$
\tau=\frac{1}{\sqrt{3}}\left[\left(\sigma_{1}-\sigma_{2}\right)^{2}+\left(\sigma_{2}-\sigma_{3}\right)^{2}+\left(\sigma_{3}-\sigma_{1}\right)^{2}\right]^{1 / 2}
$$

The use of the parameter $T$ provides a true perspective in a geometricsl sense for the stress space surfaces and its magnitude at a point on each surface is a function of the various combinations of deviatoric stress components as well as the mean stress. Figure (2) shows how the direction and magnitude of the deviatoric stress vector would be oriented for the failure conditions under pure shear, uniaxial tension, and equal biaxial tension states of stress. 


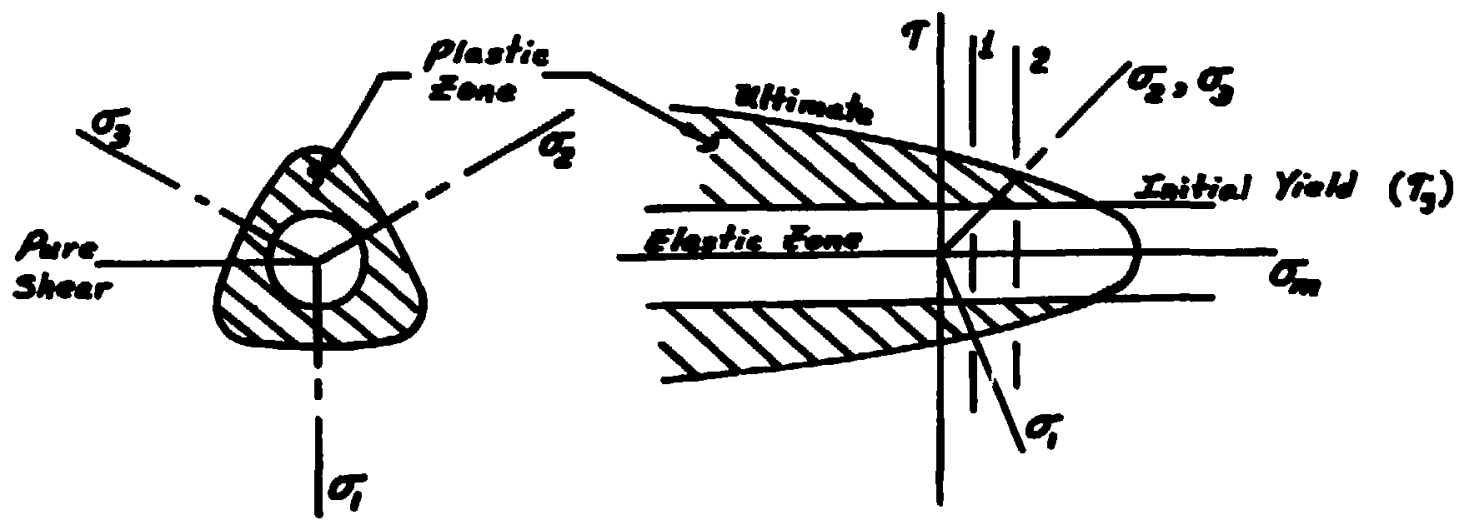

Figure 1

Dual Characterization Stress Space Model 


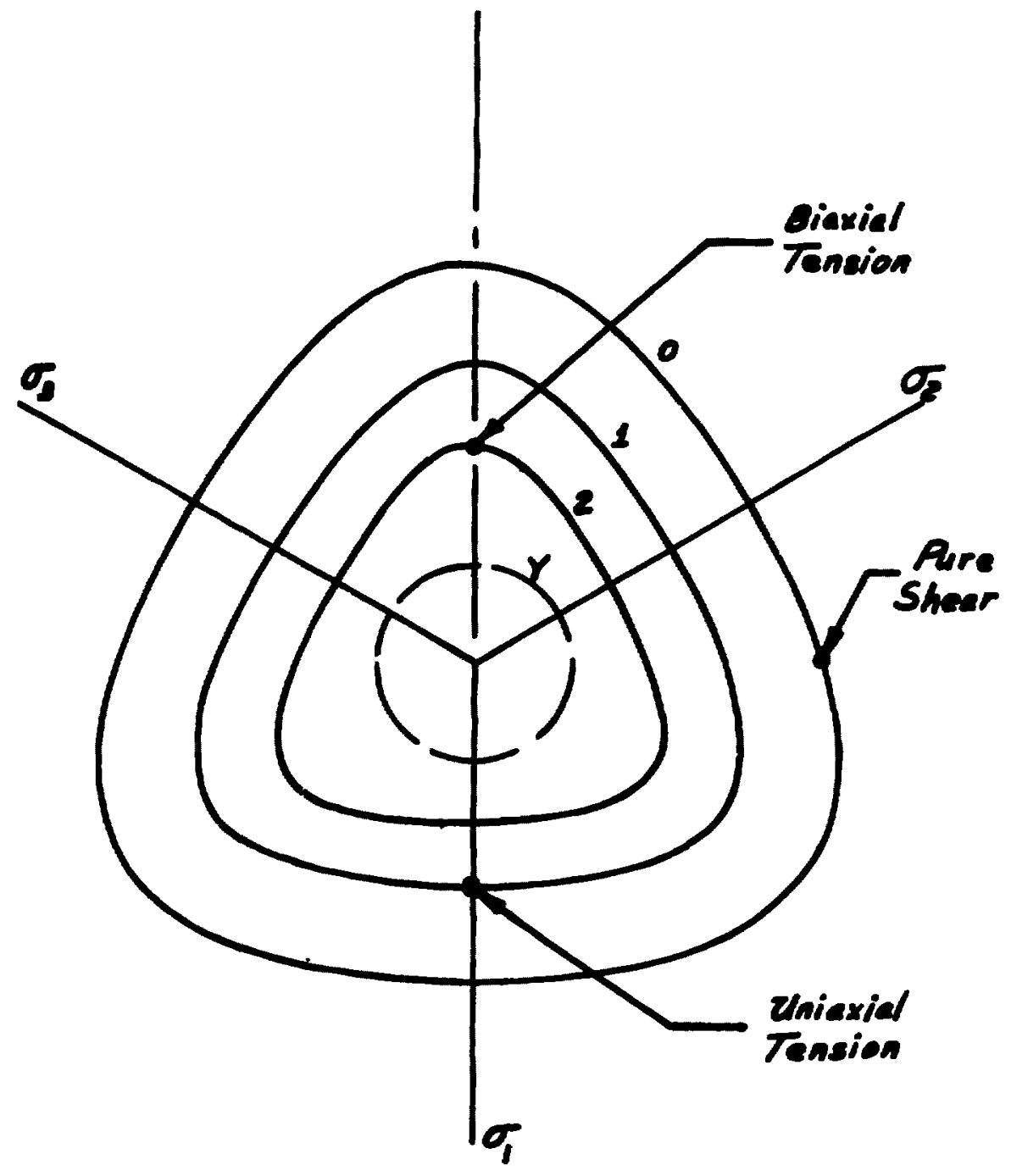

Figure 2

Deviatoric Strength Contours for Various Deviatoric Planes 
Extension of this stress-space nodel to predict strain at Eracture requires a failure stress to fallure strain transformation model. A stress-strain model is also required in the stress analysis but the needs are different. In the stross analysis the entire path of a stress-strain curve must be accurately traced while correlation of ultinate strain to ultimate stress needs to only model the terminal points on such a curve. A truncated power series, Equation (5), is proposed to correlate these terminal point data. A general stress-strain curve is illustrated in Figure (3) as an aid in graphical interpretation of terms in this equation.

$$
\bar{\varepsilon}_{p}=a+b\left(\frac{\tau_{u}-\tau}{\tau_{y}}\right)+c\left(\frac{\tau_{u}-\tau}{\tau_{y}}\right)^{2}+\ldots
$$

(Recall that $\tau_{u}=\tau_{u}\left(\sigma_{m}\right.$, loading path $)$ ) Plastic strain is assumed to be measured by $\bar{\varepsilon}_{p}$ and $i s$ assumed to be totally driven by the deviatoric (flow) stress. In the general curve, an unstable plastic strain increnent can be equated to the constant term in the series of Equation (5). A varying slope of the stress strain curve in the terminal regirn can be accommodated by the second and third terms. For materials which do not exhibit an unstable flow region, as depicted in Figure (4), the constant tern, a, would be zero. This latter condition is assumed appropriate for analysis of the beryllium data. The other constants, b and $c$, remain to be quantified in this case and strain data which correspond to two independent 


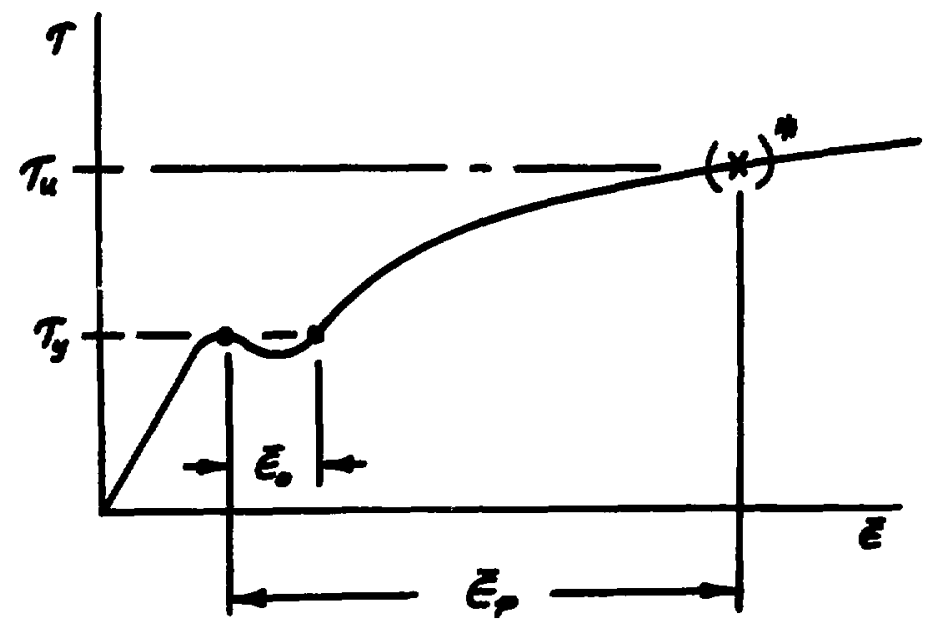

Figure 3

General Stress - Strain Curve

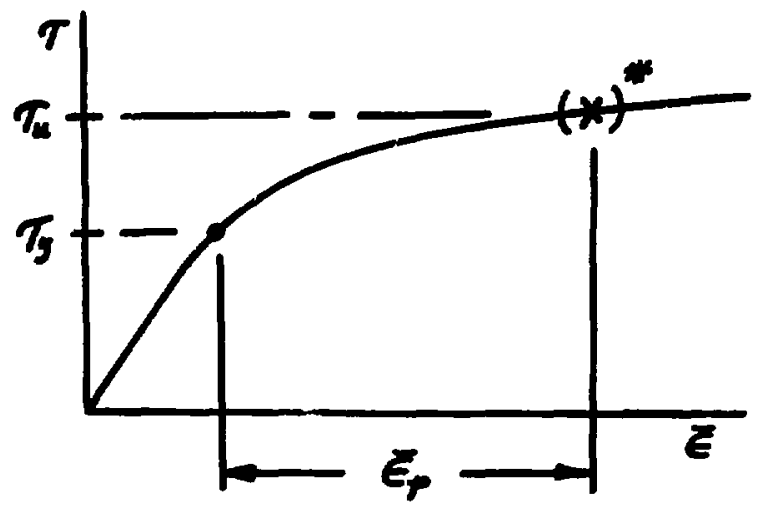

Figure 4

Stable Stress - Strain Curve for Hork Hardening Materials

* Note that $\tau_{u}$ and $\bar{\varepsilon}_{p}$ are variables which depend upon $\sigma_{m}$ and the loading path to fracture. The points $(X)$ located on these curves are shown for illustration purposes. 
stress conditions necessary to quontify the stress space model were used to calculate values for these constants.

The ultimate deviatorlc stress level, Tu, can be calculated from the cubic model of Ref. (4). The magnitude of deviator lc stress at initial yield is denoted by $\tau_{y}$. The corresponding plastic strain at frasture can then be calculated with Equation (5). Equation (5) offers a simple form for tre ting both unstable flow and a hardening rule where hardening either increases or decreases with increased plastic strain. As shown later in this report this simple equation quite accurately correlotes the beryllium strength and ultimate strain data.

In summary, two independent states of shress with corresponding measurements of effective plastic strain are required to define the constants in these equations. Por the two grades of beryllium, uniaxial tension and pure shear data were selected. The remaining data points were used to test the ability of the mathematical models to predict the measured plastic strain at fracture.

\section{DATA ANALYSIS}

The following steps were taken in analyzing the strain and stress at fracture for the two grades of beryllium reported in Reference (5): 
1. The ultimatc and yield strengths were previously correlated with tis? Aual characterizition methods presented in Refe * : (4). Only those curves used in the correlation of strain data are repeated in this report. These ace Figures (5 and 6) which are plots of deviatorte vs. mean stress strength curves for the Be-XN5OC and Be-P1 data. The bounds were determined from calculations of plus and minus two standard deviations on the ingut data. Uniaxial tension and pure shear were used for these ultinate strength input data. Other curves in Reference (4) show that these methods provided accurate bounds for the biaxial strength data.

2. The complete data sets were separated into thrse subsets: uniaxial tension, pure shear, and the remaining otress conditions (called the "remainder"). The ultimate data were reduced to $\bar{\varepsilon}_{F^{\prime}} \tau_{u}$, and $\sigma_{m}$. To calculate $\bar{\varepsilon}_{\underline{p}}$ from only two measured components of strain, Inconpressibility, as given by equation (6), was assumed and used to calculate the third component of strain,

$$
\varepsilon_{1}+\varepsilon_{2}+\varepsilon_{3}=0
$$

where $\varepsilon_{1}$ and $\varepsilon_{2}$ are the two principal strain components reported in Reference $(5)$. 


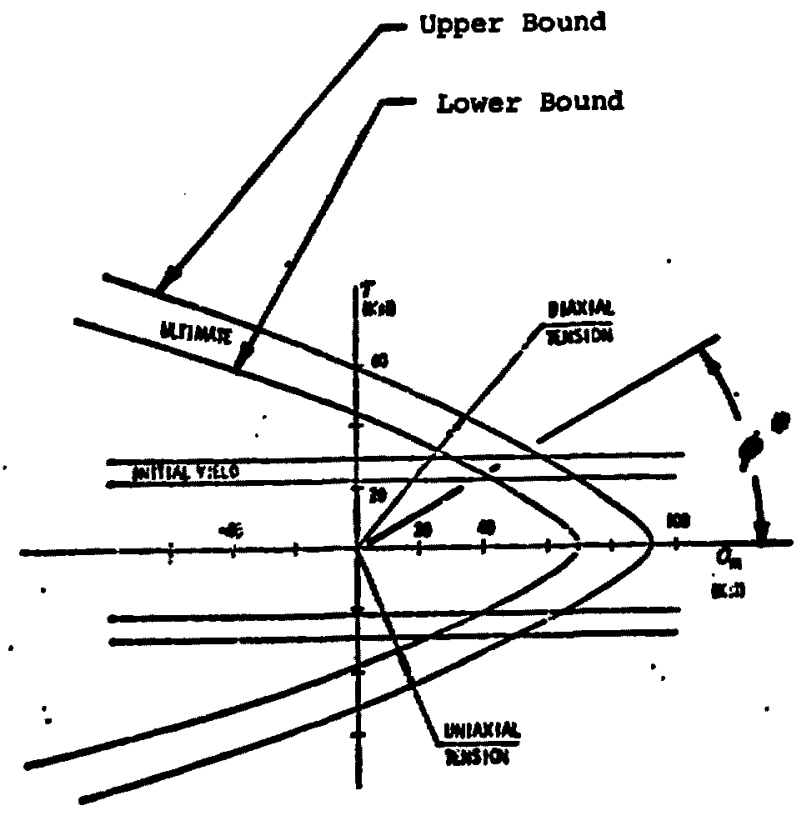

Ficure 5

Plot of Deviatoric

ve. Mean Stress Strengths

for $B e-X N-50 C$

* Note that $\sigma_{m} /=\cot (\phi)$. Data are plotted versus this ratio $\left(\sigma_{m} / \tau\right)$ in several figures later in this report. This ratio is used since it provides a convenient parameter for spanning the various stress states in $\left(\tau, \sigma_{\mathrm{m}}\right)$ stress space. 


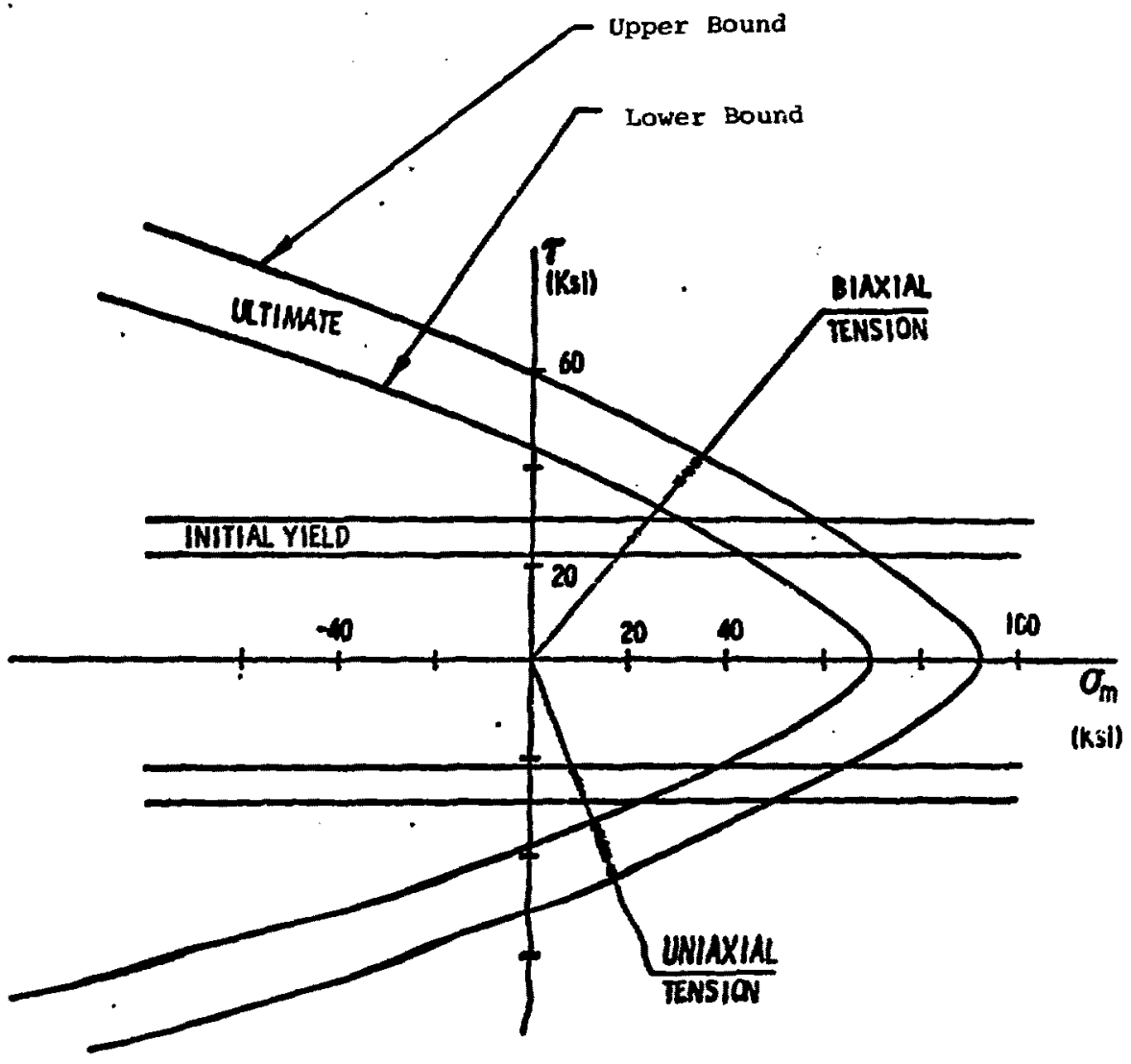

Figure 6

Plot of Deviatoric vs.

Mean Stress Strengths

for Be-Pl. 
Additionally, the strain measurements reported in Reference (5) were total component; of strain; i.e., they included the strain to 0.28 of fet yield. The effective plastic strain was computed by subtricting a constant value of strain at 0.28 offset yield from the total effective strain determined with the first of Equations (3) and the referenced measurements.

Some of the test specimens had been pre-strained but in this analysis, these various stress paths to fracture were not considered. Deviatoric stress, $\tau_{u}$, and mean stress, $\sigma_{m}$, at fracture were computed for each data point with the forms given in Equations (4 and 3 ) respectively. The deviatoric yiald strength, $\boldsymbol{r}_{y}$, was taken as the average tensile yleld strength calculater in Reference (4): $T_{y}=30.5 \mathrm{ksi}$ for Be-XN50C and $\tau_{y}=41.3 \mathrm{ksl}$ for Be-Pl.

3. Constant (a) in Equation (5) was set to zero and constants (b and $c$ ) were determined from the uniaxial tension and pure shear data. Average values of the reduced data, $\boldsymbol{T}_{\mathrm{u}}$ and $\bar{\varepsilon}_{\mathrm{p}}$, were calculated for the separate input data sets; uniaxial tension and pure shear. These two sets of average values were inserted into Equation (5) to form two simultaneous algebraic equations. These were solved for the constants (b and c). 
4. Equation (5) was normalized by dividing both sides of this equation with the right hand side to develop a function of both stress and strain which should provide a dimensionless quantity for each data point. These data should be centered about unity if the correlation scheme is useful; i.e.,

$$
F=\frac{E_{p}}{b\left(\frac{\tau^{-\tau} y}{\tau y}\right)+c\left(\frac{\tau^{-\tau} y}{\tau}\right)^{2}}
$$

note that $F$ is unity when average values of $\bar{\varepsilon}_{p}$ and $\tau_{u}$ from the input drta sets are inserted into Equation (7). Standard deviation of $F$ was calculated for the completed set of input data. Calculated values of $b, c$, and the standard deviation of F are given in Table (I) for the two sets of measured data. Pigures ( 7 and 8 ) are scatter plots of these reduced input data vs. $\sigma_{m} / \tau$ for the two materials. Plus and minus two standard deviation values of $F$ are shown with the vertical lines. Figures ( 9 and 10$)$ show the scatter in the reduced values of plastic strain vs $\sigma_{m} / \tau$.

5. To test the applicability of Equation (7), values of $F$ were computed for the additional data. Figures (11 and 12) 


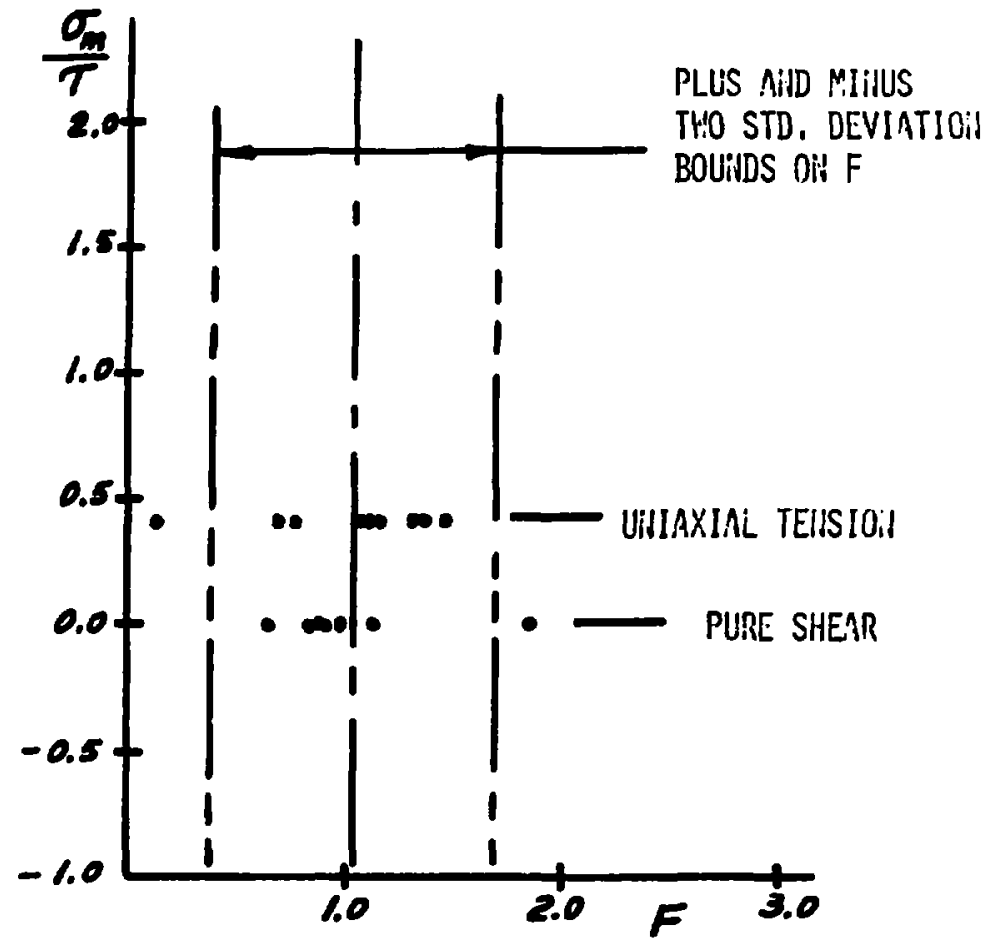

Figure 7

Plot of Reduced Be-XN50C Input Data 


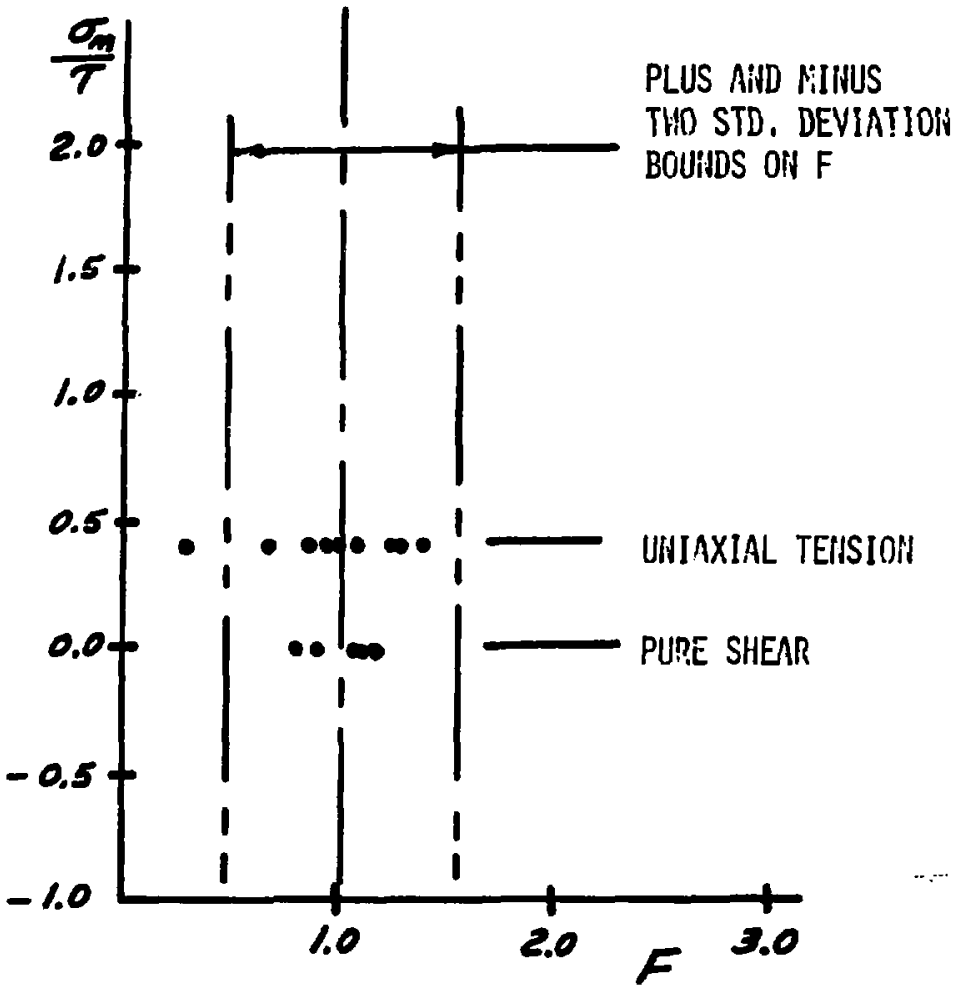

Figure 8

Plot of Reduced Be-Pl Input Data 


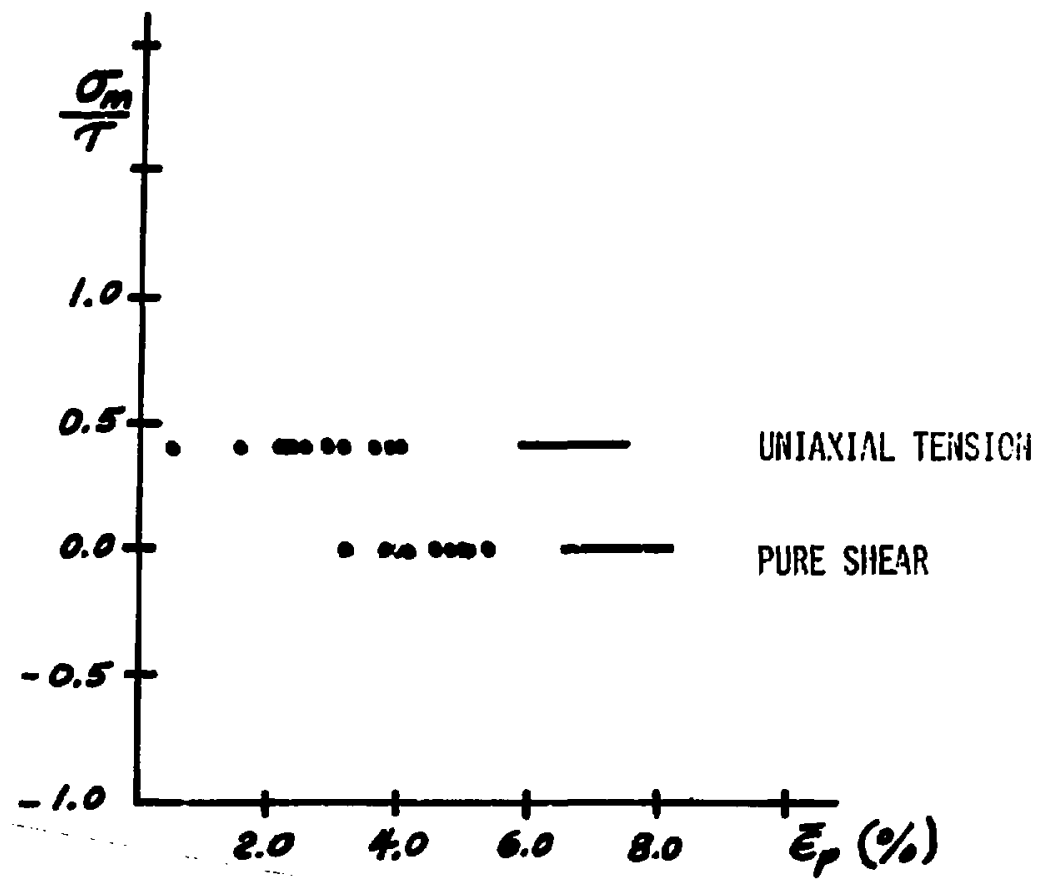

Figure 9

Plot of Be-XN50C Effective Plastic

Strain vs. $\sigma_{\mathrm{m}} / T$, Input Data 


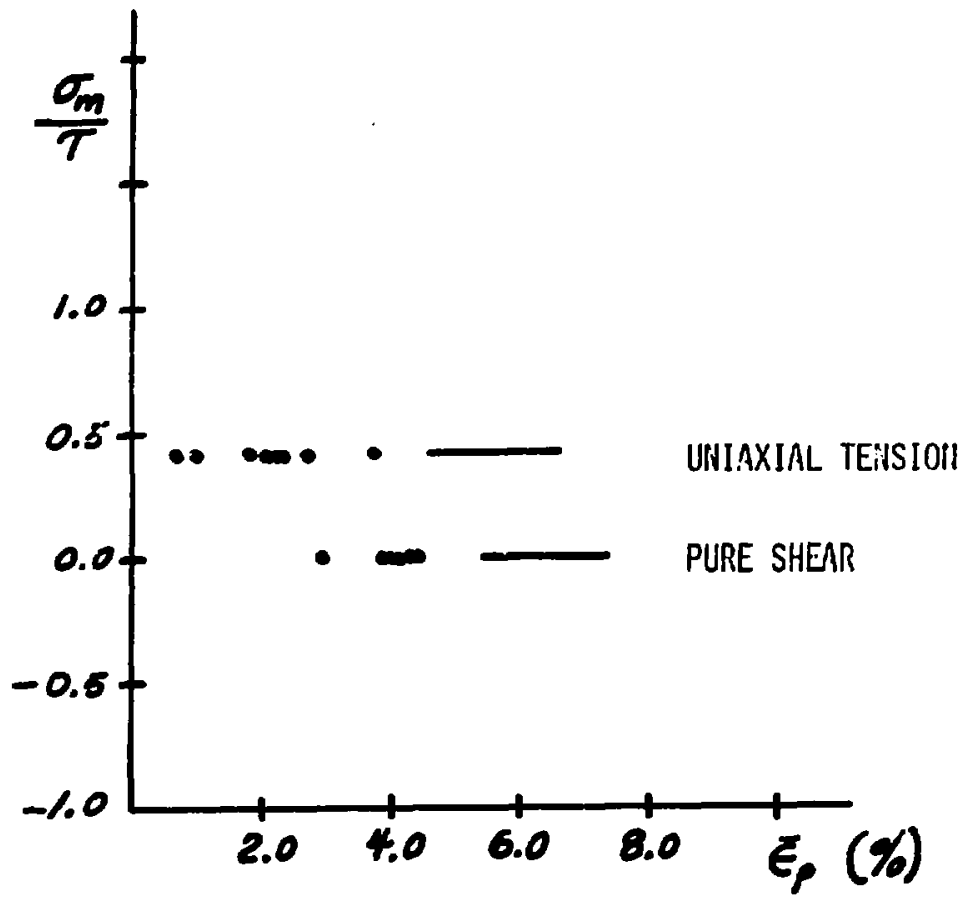

Figure 10

Plot of Be-Pl Effective Plastic

Strain vs. $\sigma_{\mathrm{m}} / T$, Input Data 


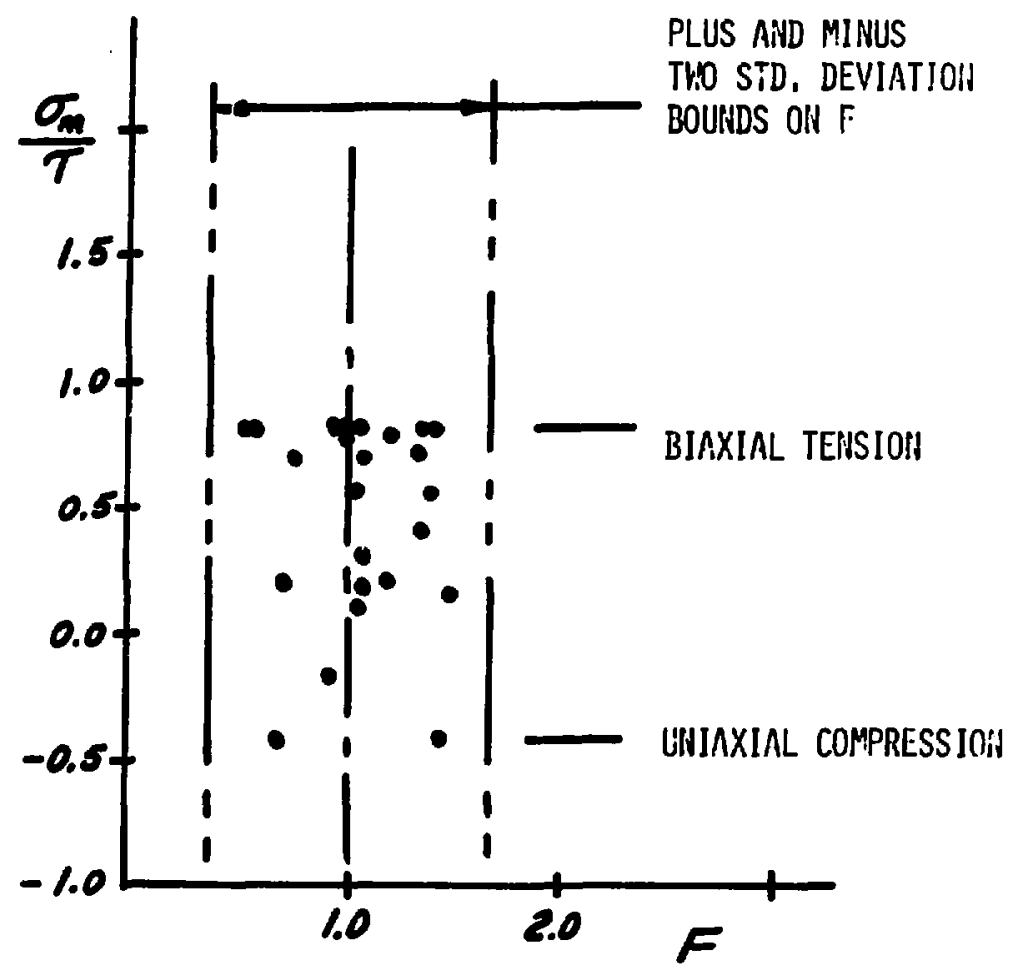

Figure 11

Plot of Reduced Be-XN50C Data,

Remainder Data set 


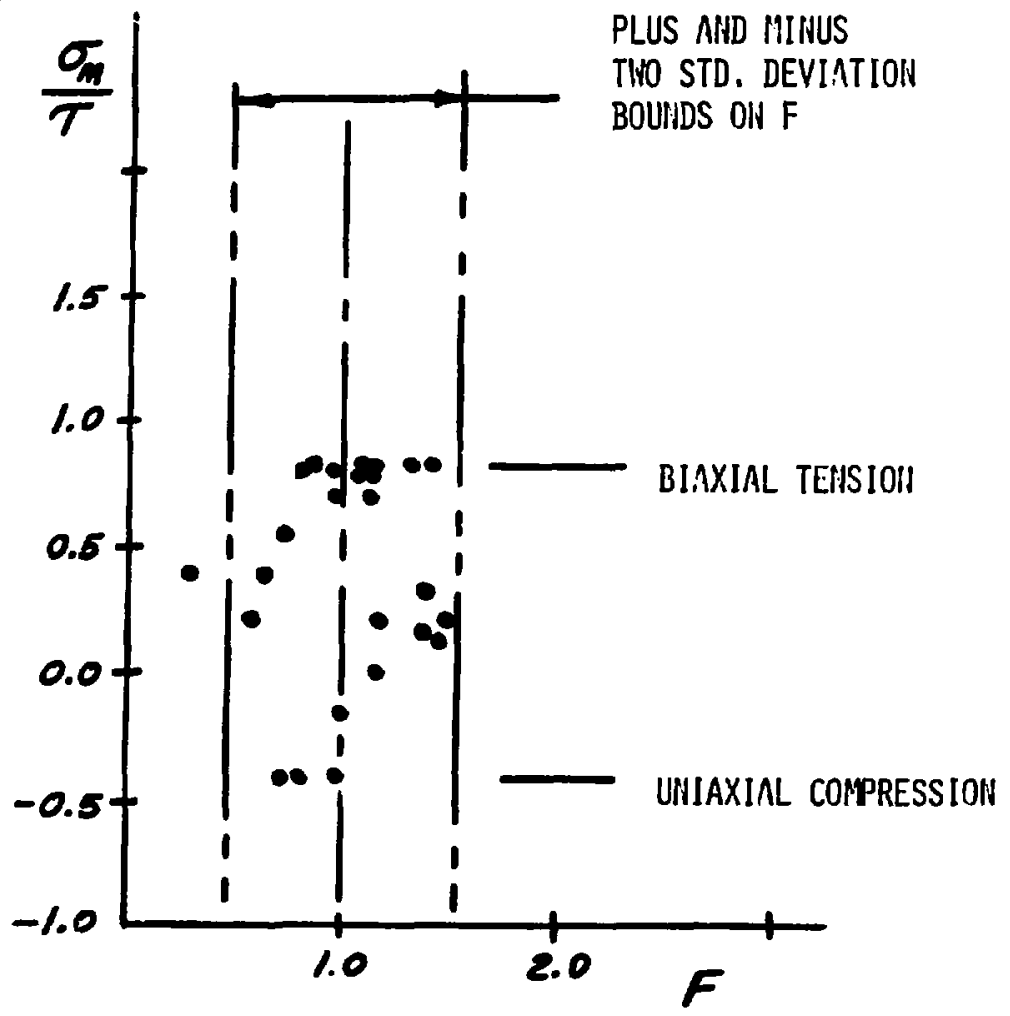

Figure 12

Plot of Reduced Be-Pl Data, Remainder Data Set 
are plots of $\mathrm{F}$ vs. $\sigma_{\mathrm{m}} / \mathrm{T}$ for these data. The bounds are those previously calculated from the selected input data. Note that these data are essentially contained and centered within the bounds. Histograns of these data were constructed to further test the assumption made in applying Equation (7) through Figures $(7,8,11$ and 12) that the complete et of data is normally distributed about the mean value of unity. Pigure (13) is a histogran plot for the Be-XN50C data set. Sinilar results were obtained for the Be-Pl data and are shown in Figure (14).

\section{TABLE I}

Calculated Constants for Two Grades of Be for Use in Eq (5)

\begin{tabular}{|l|c|c|c|c|}
\hline & b & c & $\begin{array}{c}\text { Std. Daviation } \\
\text { of F Es } \\
\text { Input Data }\end{array}$ & $\begin{array}{c}\text { Number of } \\
\text { Input Data } \\
\text { Points }\end{array}$ \\
\hline XN50C & 4.442 & 0.20 & 0.326 & 23 \\
\hline P1 & 3.079 & 1.792 & 0.265 & 17 \\
\hline
\end{tabular}

6 To test the transformation from stress space to effective plastic strain, the outer and inner ultimate strength bounds from Figures (5 and 6) were transformed with Equation (5) and these are displayed in Figures (15 and 16). The stress vector orientation was preserved in these plots. The biaxial tension and uniaxial tension data points are also plotted. Note that the neasured blaxial 


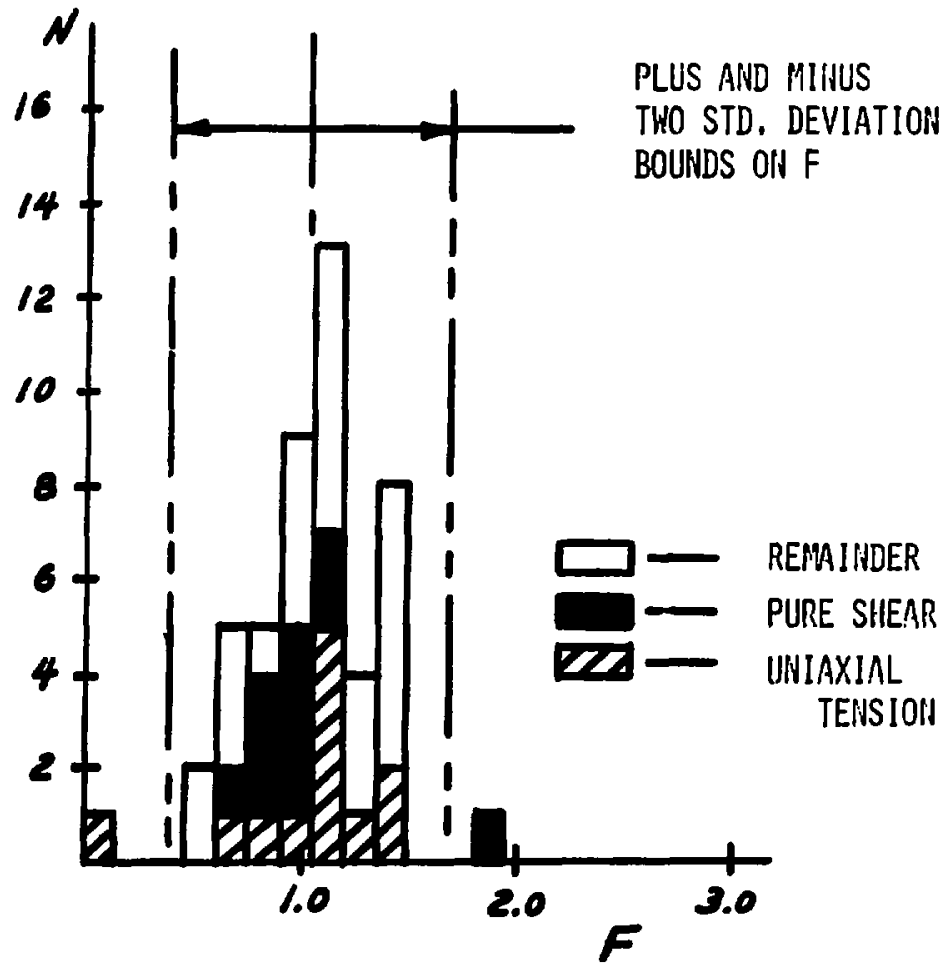

Figure 13

Ilistogram plot of Reduced Be-XN50C Data 


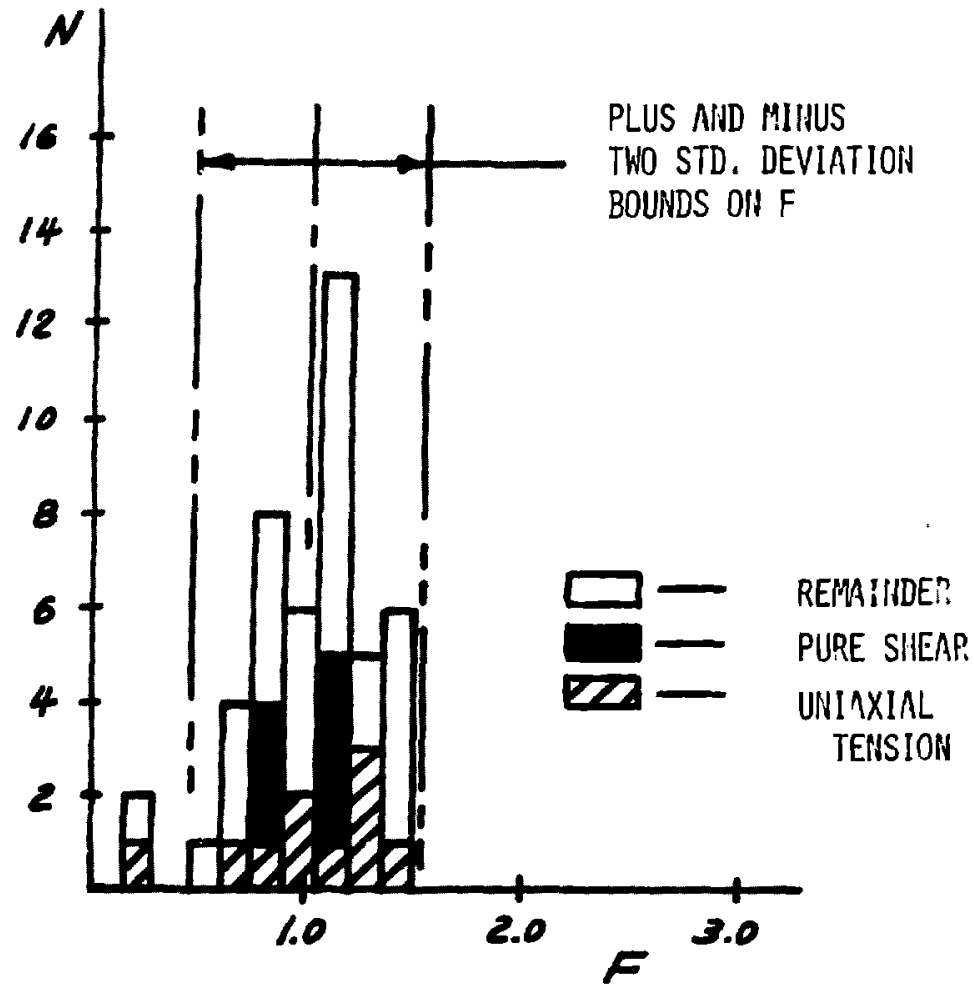

Figure 14

Histogram Plot of Reduced Be-Pl Dat: 


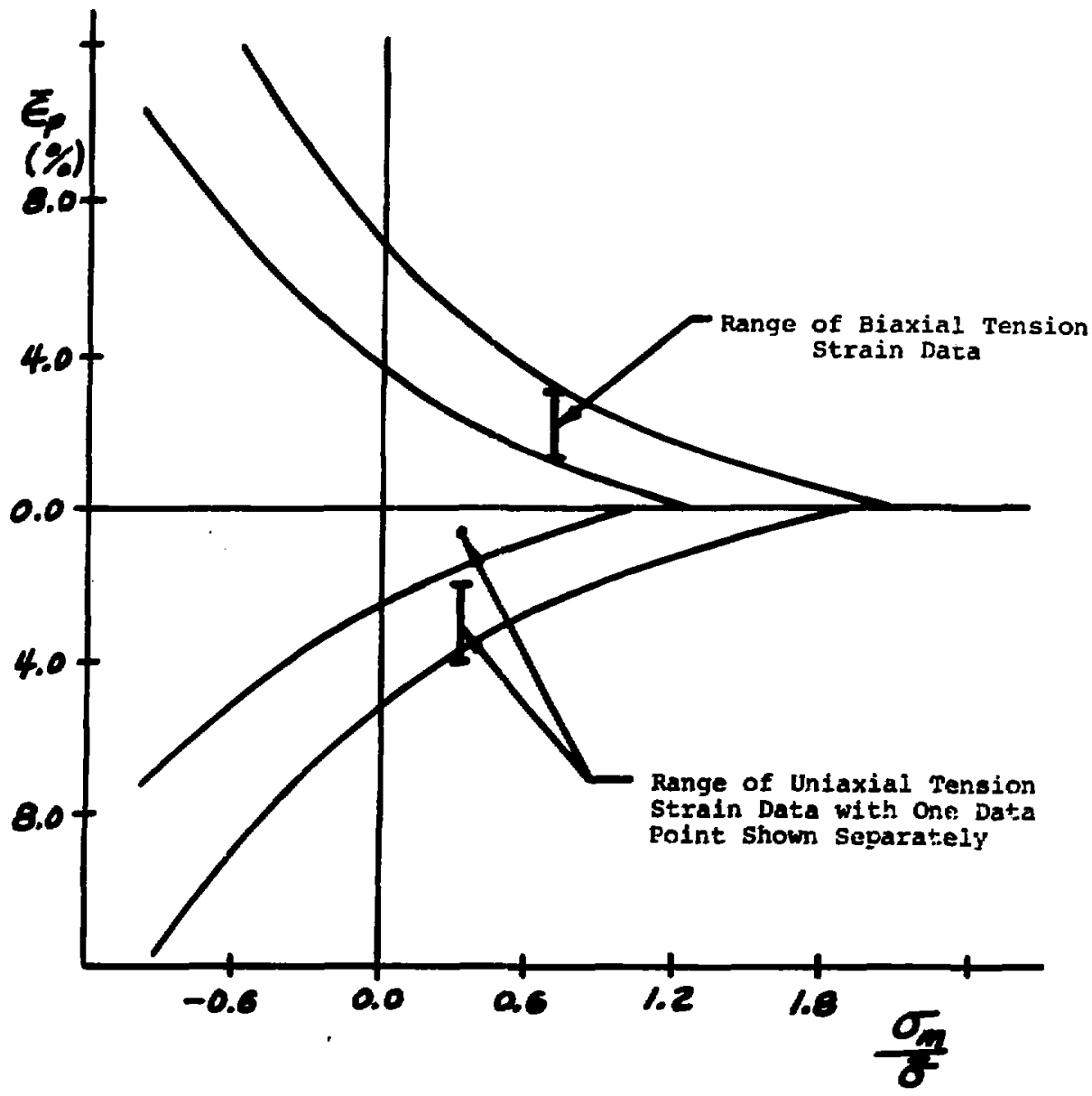

Figure 15

Transformed Stress Space Bounds, Be-XN50C,
Plotted vs. $\sigma_{\mathrm{m}} / \bar{\sigma}$ 


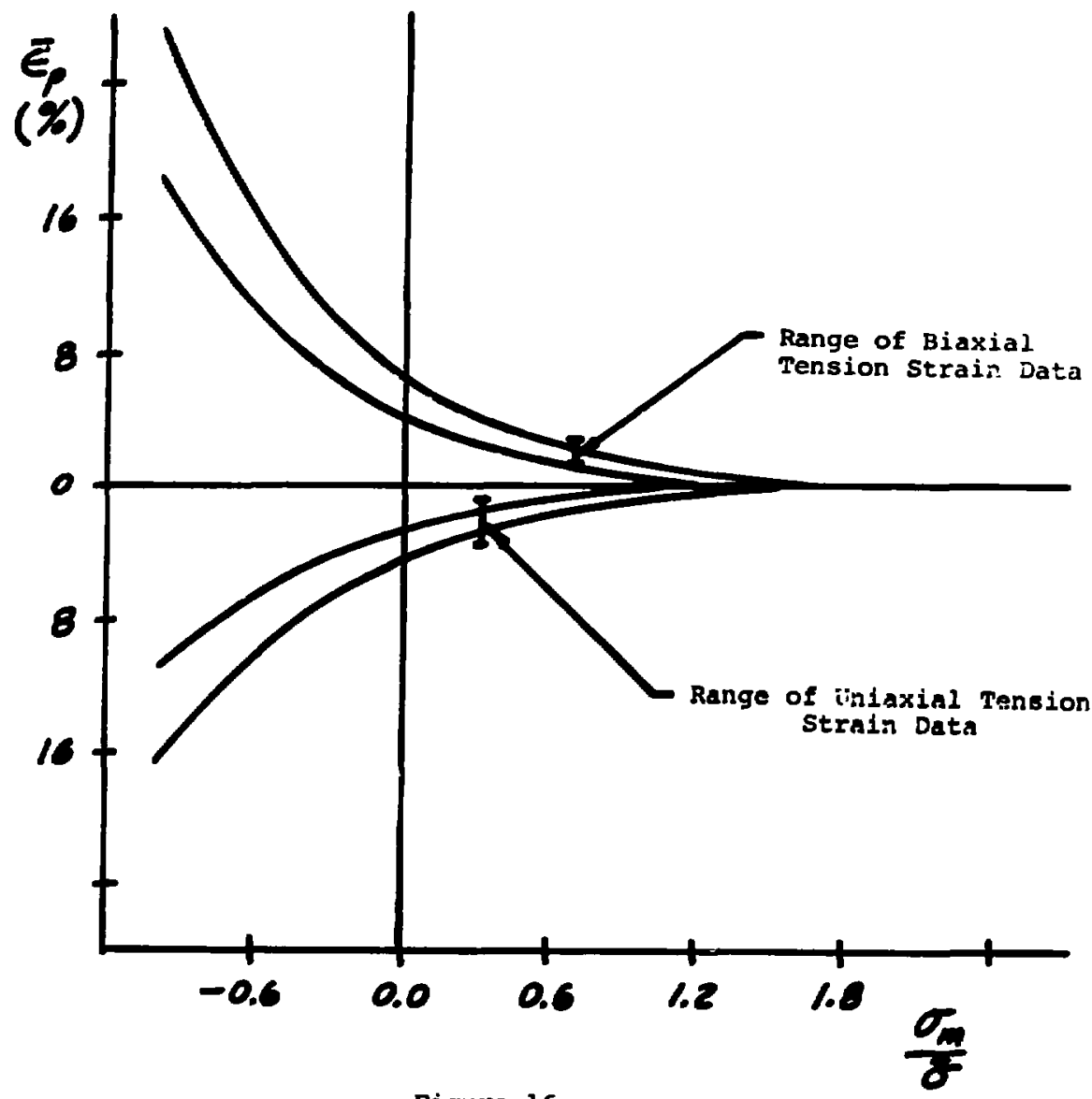

Figure 16

Transformed Stress Space Bounds, Be-Pl, Plotted vs. $\sigma_{\mathrm{m}} / \sigma$ 
tension strain data are compared with bounding curves which are developed totally from the stress-space model, uniaxial tension and pure shear strengths, calculated variations in these input strength measurements, and the failure strain to tailure stross rule given by Equation (5). The uniaxial tension data were used as part of the input data to the modeling equations but the stress-space orientation of these data relative to the biaxial tension data should be noted. This rotational significance, illustrated in Figure (2), is attributed to the third stress invariant which was included in the stress space model.

Another method of illustrating transformed strain at fracture is displayed in Figures (17 and 18). The deviatorle stress along the average ultimate surface was transformed to strain using Equation (5) and was plotted versus mean stress normalized with the average ultimate tensile strength. Plus and minus two seandard deviation strain scatter bounds were computed from the uniaxial tension and pure shear data and these were added to and subtracted from the calculated average values to form the displayed scatter bounds. The reduced biaxial tension data are plotted to illustrate how well they are contained with these predictive methods. It is interesting to note that the effective plastic strain at failure is essentially a linear function of mean stress at failure for these grades of beryllium. 


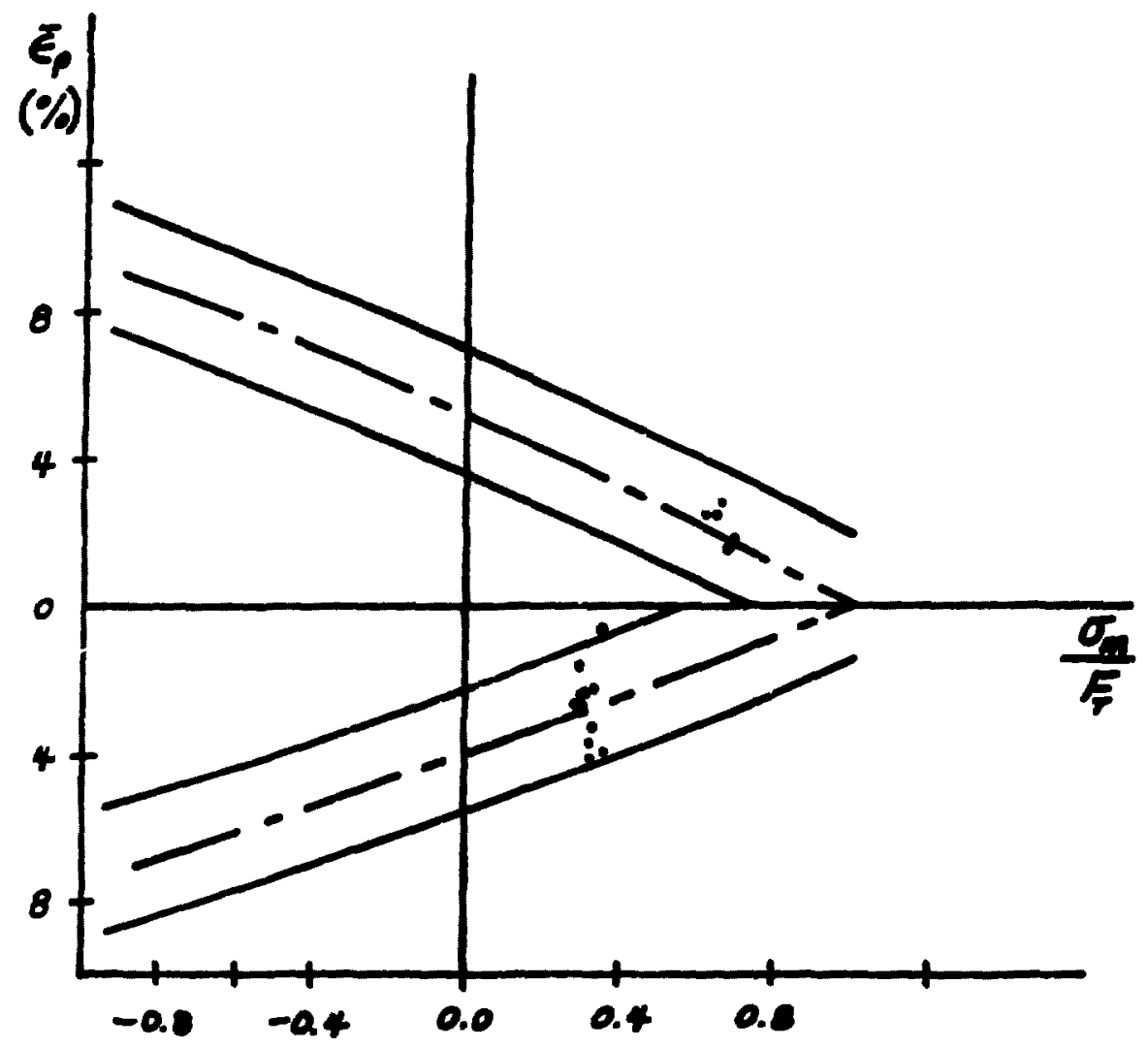

Figure 17

Transformed Stress Space Bounds, Be-XN50C, Plotted vs, $\sigma_{m} / F_{T}$ 


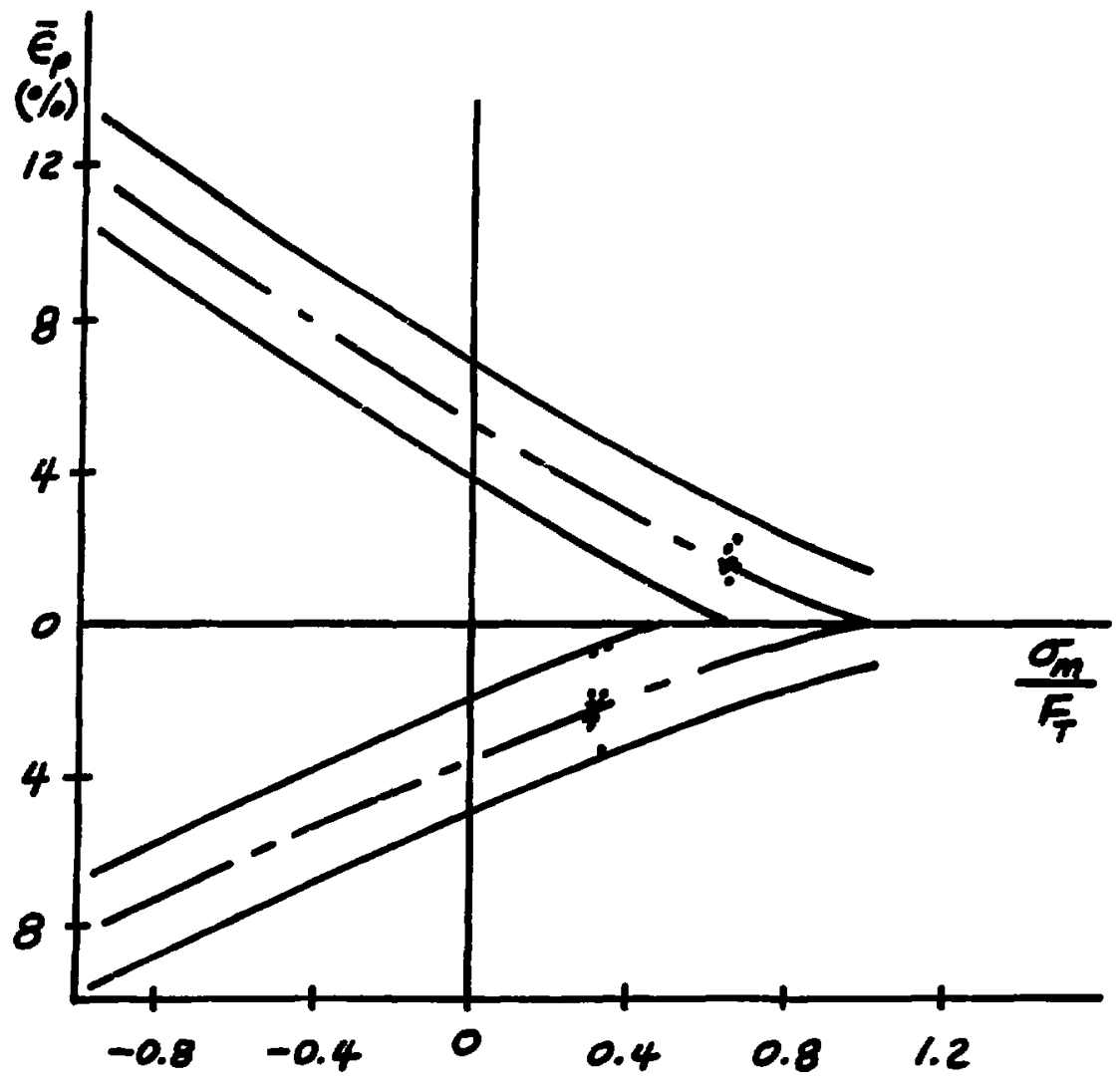

Figure 18

Transformed Stress Space Bounds, Be-rPl

Plotted vs. $\sigma_{\mathrm{m}} / \mathrm{F}_{\mathrm{T}}$ 
7. The data for the two grades of beryllium were analyzed in a similar fashion as that described in paragraphs 1 through 6 but with the use of the exponential model given in Equation (2). A normalized function of stress and strain similar to that given by Equation (7) was used, 1.8.,

$$
F_{e}=\frac{E_{p}}{A \exp ^{-k}\left(\sigma_{m} / \delta\right)}
$$

Computed values of $A$ and $k$ determined Erom the uniaxial tension and pure shear data are listed in rable (II). A standard deviation on the selected input data was also calculated for Fe and it is listed in this table. Figures (19 and 20$)$ are plots of these reduced input data vs. $\sigma_{m} / T$.

TABLE II

Calculated Constants for Two Grades of Be for Ose in Eq. (2)

\begin{tabular}{|l|c|c|c|c|}
\hline & A & $k$ & $\begin{array}{c}\text { Sta. Deviation } \\
\text { of E for Input } \\
\text { Data }\end{array}$ & $\begin{array}{c}\text { Number of } \\
\text { Input Data } \\
\text { Points }\end{array}$ \\
\hline XN50C & 4.480 & 1.299 & 0.2877 & 23 \\
\hline P1 & 4.104 & 1.654 & 0.321 & 17 \\
\hline
\end{tabular}




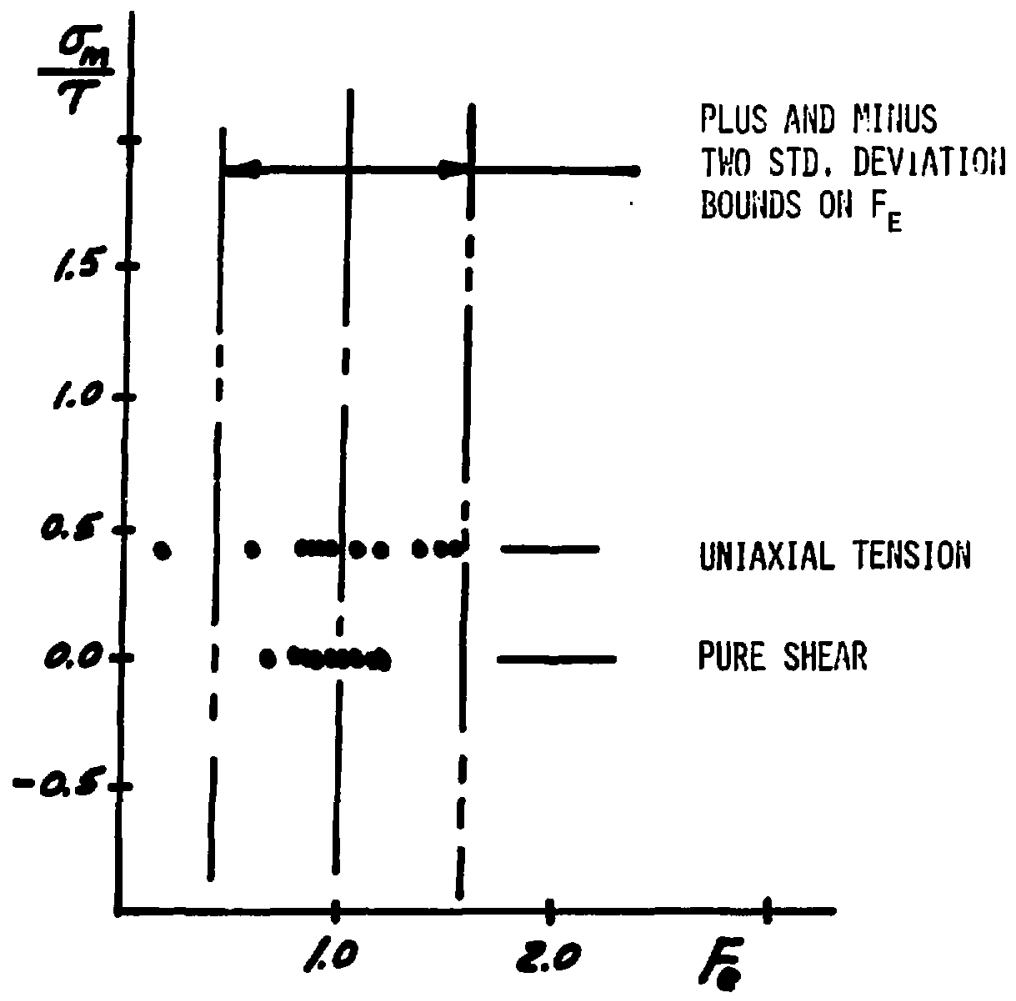

Figure 19

Plot of Reduced Values of $F_{e}$

For Be-XN50C, Input Data 


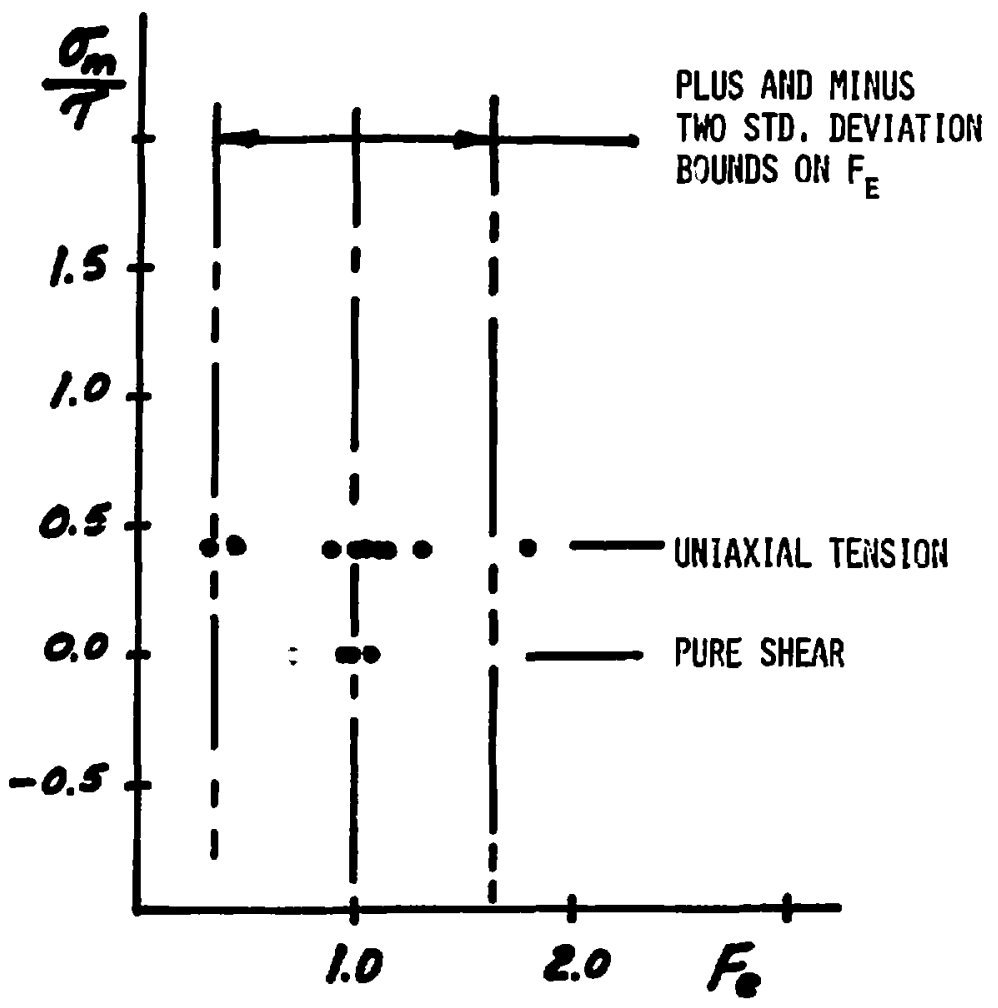

Figure 20

Plot of Reduced Values of $\mathrm{F}_{e}$ For Be-Pl Input Data 
8. Values of $F_{e}$ were computed for the additional data using Rquation (B) and these are plotted in Figures $(21$ and 22$)$. These data are not as well contained within the expected bounds as those shown in Figures (11 and 12). In addition, the central values are shifted from unity. A histogran of the reduced Be-XN50C data is shown in Figure (23). Figure (24) is a histogram of the reduced Be-PI data.

9. Figures (25 and 26) are plots of Equation (2) and the reduced strain data vs. $\sigma_{m} / r$ for the two materials. 


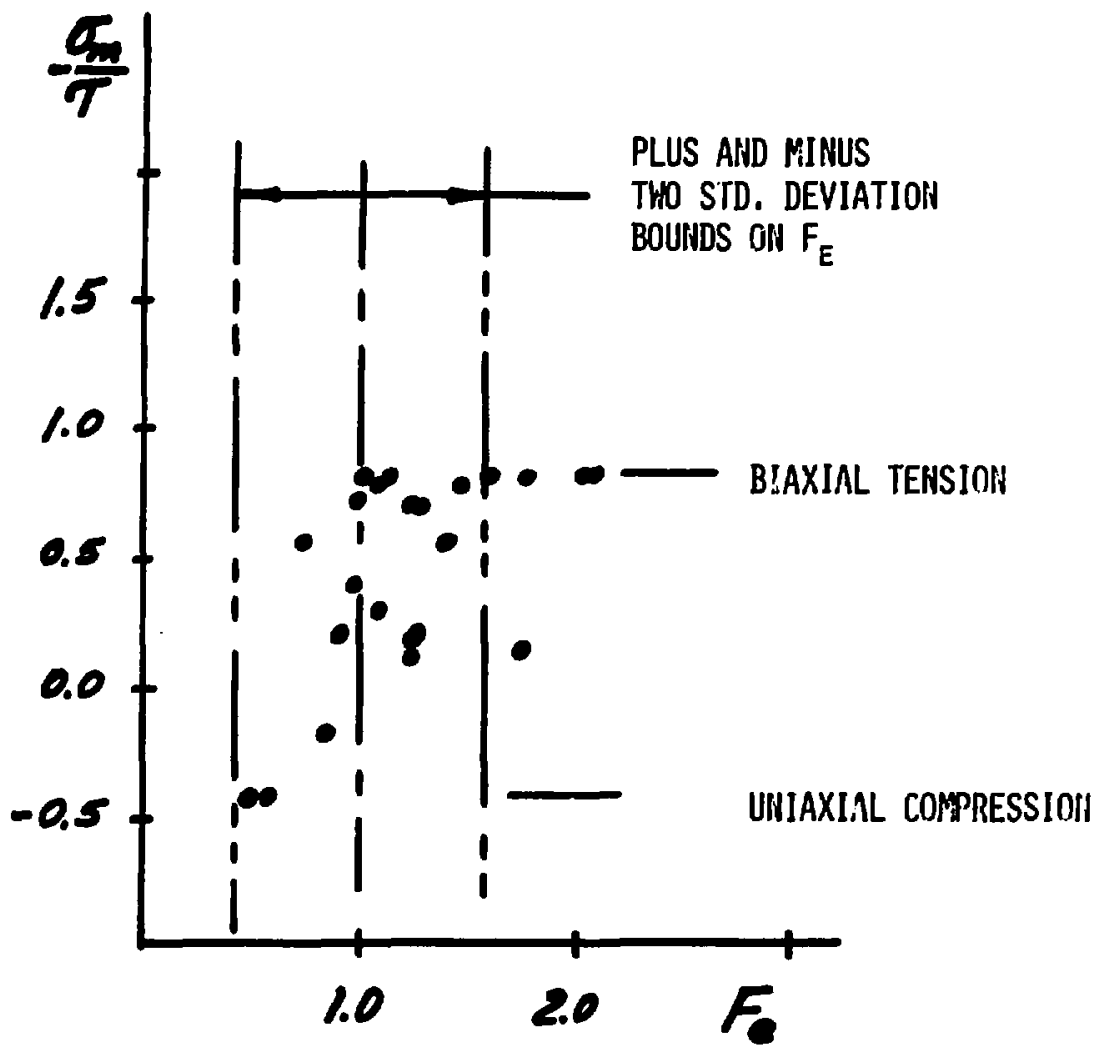

Figure 2.1

Plot of Reduced Values of $F_{e}$. Be-XN50C, Remainder Data Set 


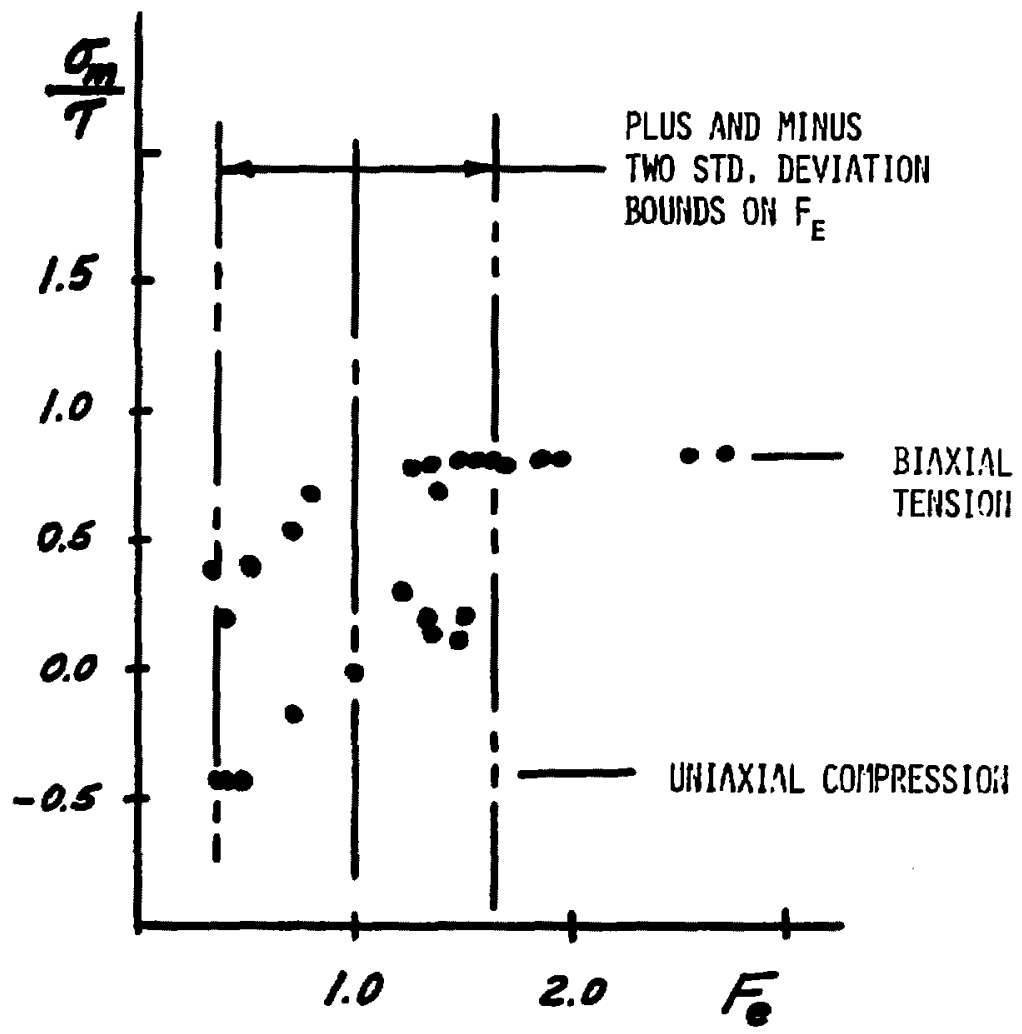

Figure 22

Plot of Reduced Values of $F_{e}$. Be-Pl, Remainder Data Set 


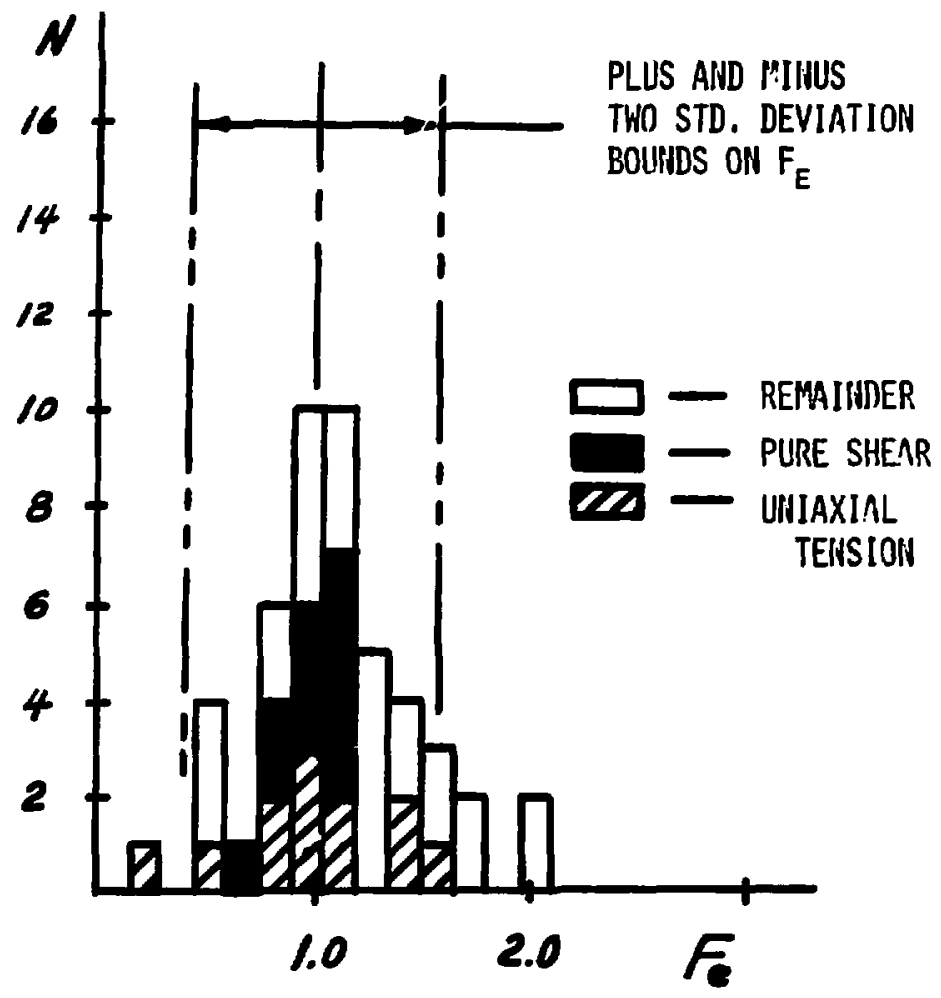

Figure 23

Histogram Plot of Reduced Be-XN50C

Data, Exponential Model 


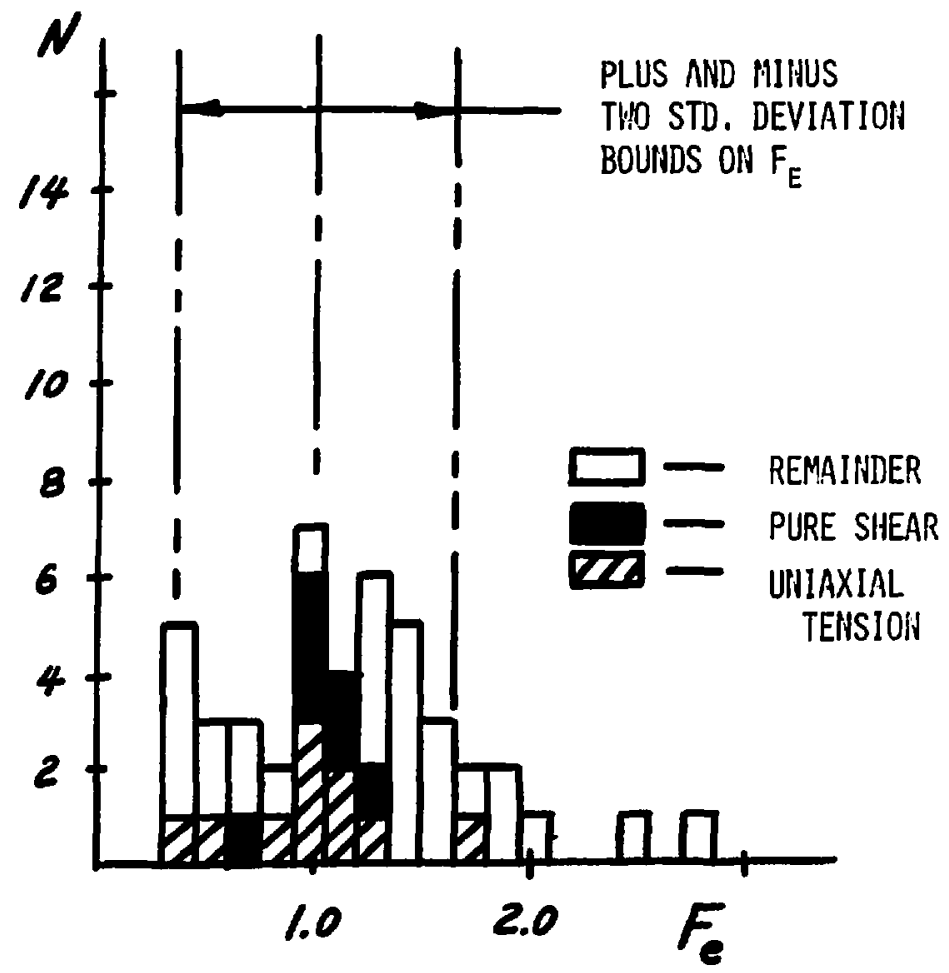

Figure 24

Histogram Plot of Reduced Be-Pl Data, Exponential Model 


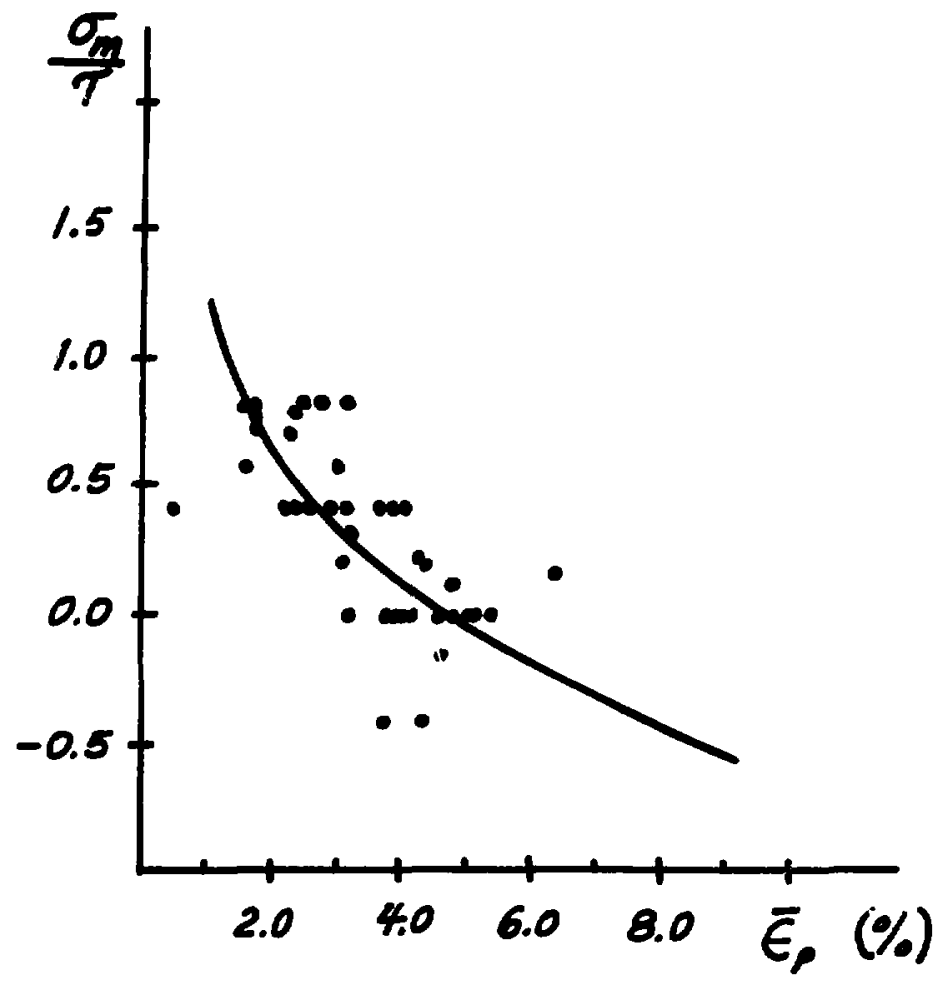

Figure 25

Plot of $\vec{E}_{p}$ va. $\sigma_{m} / \tau$ for Be-XN50C Data, Compared with Exponential Model 


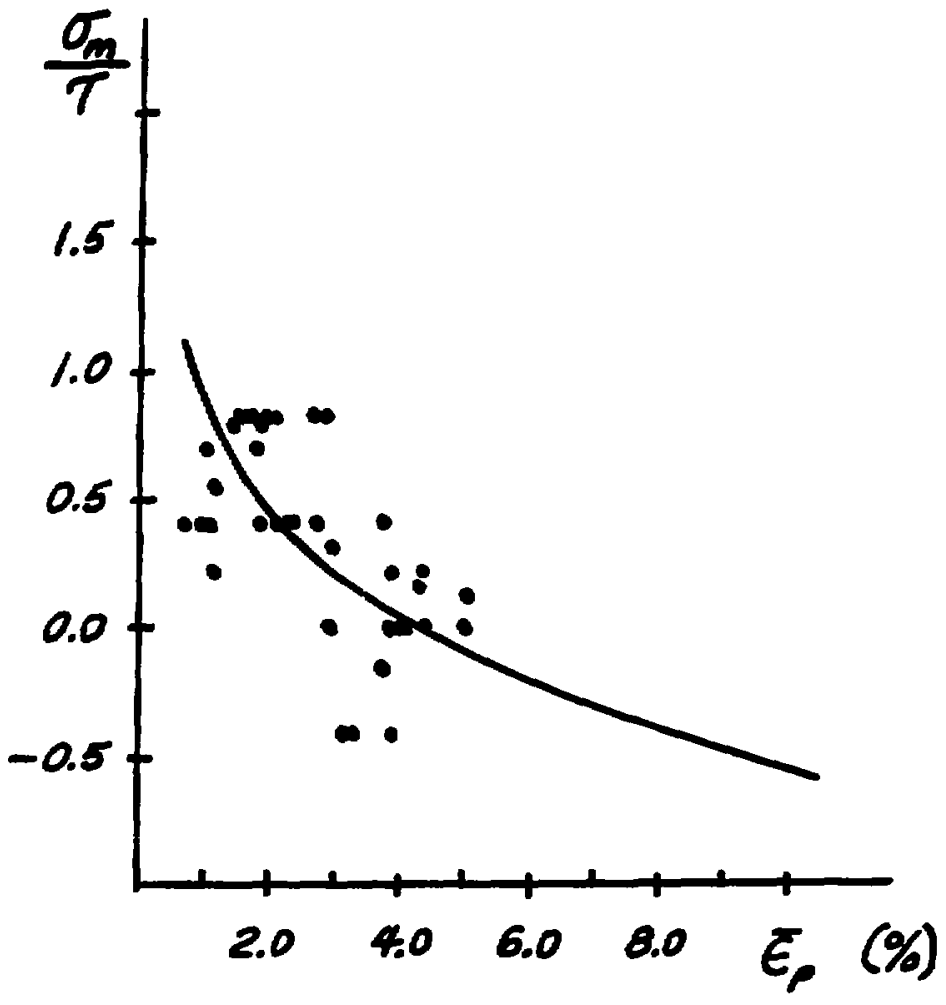

Pigure 26

Plot of $\bar{\varepsilon}_{\mathrm{p}}$ vs. $\sigma_{\mathrm{m}} / \mathrm{T}$ for Be-Pl Data, Compared with Exponential Model 
CONCLUSIONS

1. Referenced measurements of ultimate stresa and strain taken from two grades of beryllium are accurately correlated with Equation (5). This equation, used in concert with the dual characterization strength model. leads to an accurate strain at fracture prediction technique. These results generally follow the exponential mean stress model but maintain essential vector orientations of stress and strain at fracture.

2. The exponential mean stress model, Equation (2), generally follows the measured data plots but suffers from $108 s$ of stress vector orlentation effects.

3. The methods used in developing Figures (27 and 18) lead to an apparently useful method of determining a lower bound (for reliable design purposes) on plastic strain at fracture. 
REFERENCES

1. Mcclintock, F. A., "A Criterion for Ductile Fracture by Growth of Holes, "J. Appl. Mech., June 1968, pp. 363-371.

2. Rice, J. R., and Tracey, D. M., "On the Ductile Enlargement of Voids in Triaxial stress Fields," J. Mech. Phys. Solids, June 1969, Vol. 17, No. 3, pp. 201-217.

3. Hancock, J. W., and Mackenzie, A. C.. "On the Mechanisms of Ductile Pailure in High-strength Steels Subjected to MultiAxial Stress-states," J. Mech. Phys. Solids, 1976, Vol. 24, pp. 147-169.

4. Priddy, T. G., Benzley, S, E., and Johneon, R, L., "The Dual Characteristics of Yield and Ultinate Strengths as Applied to Two Grades of Beryllium, "SAND77-0122, National Technical Information Service, Springfield, Va., Rebruary 1977.

5. Uindholn, U. S., Yeakley, L. M., Davidson, D. L., "Biaxial strength Tests on Beryllium and Titanium Alloys," AD/A-002137, Distributed by NTIS, U. S. Dept. of Comerce, Springfield, Va., July 1974 .

5. Priddy, T. G., "A Eracture Theory for Brittle Anisotropie Materials," J. of Engr. Matl's and Tech., April 1974, po. 91-96. 